\title{
Health promotion for Latin Americans with intellectual disabilities
}

\author{
Georgia C Frey, PhD, ${ }^{(1)}$ Viviene A Temple, PhD.(2)
}

\author{
Frey GC, Temple VA. \\ Health promotion for Latin Americans \\ with intellectual disabilities \\ Salud Publica Mex 2008;50 suppl 2:SI67-SI77.
}

\begin{abstract}
In response to the emerging global concern regarding health and people with intellectual disabilities (ID), several developed countries have established national initiatives to address the unique health needs of this population segment. However, most people with ID reside in countries with developing economies, such as many Latin American countries, yet there is virtually no information on the health of people with ID in these regions. Countries with developing economies face distinct challenges in promoting health among this population segment that may preclude adoption or adaptation of policies and practices developed in regions with established economies. This paper will address the issue of health promotion among people with ID in Latin America, an area that is undergoing significant reforms in both health care and disability rights. Information on the social and health status of Latin Americans with ID, as well as research on health promotion best practices, will be used to develop recommendations for promoting health for these individuals.
\end{abstract}

Key words: mental retardation; cognitive impairment; learning disability; developing; developed; intellectual disability; health promotion; Latin America

\section{Frey GC, Temple VA.}

Promoción de la salud para latinoamericanos con discapacidad intelectual.

Salud Publica Mex 2008;50 supl I:SI67-SI77.

\section{Resumen}

En respuesta al interés que están despertando en el mundo la salud y la persona de quienes padecen discapacidad intelectual (DI), varios países desarrollados han establecido iniciativas nacionales para atender las necesidades de salud particulares de este segmento de la población. Sin embargo, la mayoría de las personas con DI residen en países con economías en vías de desarrollo, como muchos países latinoamericanos, donde la información acerca de ellas es escasa. Los países con economías en vías de desarrollo enfrentan sus propios retos para promover la salud en este segmento de la población, los cuales pueden impedir o dificultar la adopción o la adaptación de las políticas y prácticas establecidas en países con economías desarrolladas. Este artículo está dedicado a la promoción de la salud de la gente con DI en Latinoamérica, región donde se están llevando a cabo importantes cambios tanto en la atención a la salud como en los derechos de la discapacidad. Para desarrollar recomendaciones para promover la salud de las personas con DI, se utilizará información sobre el estado social y de salud de los latinoamericanos con DI y sobre la investigación de las mejores prácticas de promoción de la salud.

Palabras clave: retardo mental; deterioro cognitivo; discapacidad de aprendizaje; en desarrollo; desarrollado; discapacidad intelectual; promoción de la salud; Latinoamérica

(I) Indiana University, Bloomington, USA

(2) University of Victoria, British Colombia, Canada.

Accepted on: November 12, 2007

Address reprint requests to: Dr. Georgia Frey, Department of Kinesiology, Indiana University, 1025 E. 7th St./HPER II 2, Bloomington, IN 47405.

E-mail: gfrey@indiana.edu 
$\mathrm{T}$ he last five years have represented significant advancement in the recognition of rights of people with disabilities across Latin America. While the major emphasis has been basic civil rights and education, the inclusion of people with disabilities in general health initiatives of various countries is emerging. This paper will focus on health promotion for people with intellectual disabilities (ID) as a specific subset of the disabled population. An overview of the health of people with ID in Latin America, as well as recommendations for promoting health among this population segment in this region will be provided. It is important to note that only resources available in English language were used for this paper. In addition, since there is a paucity of information on people with ID in Latin America, available information on the general population of people with disabilities will be included in the discussion.

\section{Intellectual disability in Latin America}

An overview of the general status of people with ID in Latin America is warranted before health promotion for this population is addressed. Global prevalence of ID is poorly understood because the condition is either not addressed in large-scale surveillance systems or inaccurately assessed, usually through queries on disability in general. ${ }^{1}$ The World Health Organization (WHO) ${ }^{2}$ indicates that $1-4 \%$ of the world population may have some level of ID, but this is difficult to confirm due to extreme variations in definition, measurement sources, measurement methodology, and culture ${ }^{1}$. However, it is certain that the incidence and prevalence of ID is highest in developing countries, primarily due to environmental, disease and nutritional risks associated with poverty that have been largely controlled in developed nations. ${ }^{1,3,4}$

The incidence and prevalence of ID in Latin America is largely unknown. The Pan American Health Organization $(\mathrm{PAHO})^{5}$ reported that $4.6 \%$ of the population under age 18 in developing countries had severe ID, compared to $0.5 \%-2.5 \%$ of those in the same age group living in countries with established economies. These figures provide little information about the scope and impact of ID in Latin America because most people with ID are classified as mild rather than severe ${ }^{6}$ and the definition of "established" economy varies greatly. Many Latin American countries possess an established economy according to the gross national product, yet most are considered developing based on standard of living and human development index assessments. ${ }^{7}$ For example, Argentina has an established economy and is one of the wealthiest Latin American countries, but the nation struggles with a high infant mortality rate. In ad- dition, large sections of the population, typically those in poorer regions, continue to be exposed to morbidity and mortality risks not observed in other developed countries. ${ }^{8}$ Thus, in many aspects Argentina is still a developing country.

In a review of basic country health profiles listed on the PAHO website, over one-half of the 20 countries and eight territories considered as part of Latin America provided data on people with disabilities, albeit most of the information was lacking in detail, depth, and scope. Of these countries, only Honduras and Mexico specifically mentioned people with ID as part of a general reference to the prevalence of physical and mental disabilities. Nicaragua is one of four countries, and the only Latin American country, that attempted to identify ID as part of the World Bank Living Standards Measurement Survey and reported a rate of 3.2 per 1000 citizens with the condition. ${ }^{1}$ The International Disability Rights Monitor (IDRM) ${ }^{9}$ published a report on the status of disability rights in the Americas, but only Chile, Paraguay, and Mexico provided estimates on the number of people with ID, and these data were considered unreliable or under representative based on the aforementioned surveillance concerns. The PAHO Health in the Americas ${ }^{10}$ publication reports that an estimated 13.8 million Latin Americans have ID, but this figure must be viewed with caution, again due to inadequate surveillance. This lack of consistent information available from centralized dissemination sites (i.e. PAHO, World Bank, IDRM) perpetuates the difficulty in understanding ID demographics in Latin America, and consequently the magnitude of need.

Difficulties in identifying ID are further confounded by a lack of consensus on definition and nomenclature. In developed countries there is ongoing debate about the meaning of intelligence and IQ as a measure of intelligence, as well as how to interpret the fact that most people with ID have no known etiology. ${ }^{11}$ The WHO International Classification of Disease-10, ${ }^{12}$ American Association on Intellectual and Developmental Disabilities (formerly American Association on Mental Retardation) ${ }^{13}$ and American Psychiatric Association ${ }^{14}$ all offer slightly different diagnostic criteria for ID. ${ }^{15}$ Terminology varies according to country and organization, and includes ID (Australia and United States), mental retardation (United States and WHO), mentally challenged (Cayman Islands), mentally handicapped (Scotland), slow learners (Belize), mental disability (Bulgaria), and learning disability (Great Britain); although ID is increasingly becoming the term of choice for many countries and agencies. Consensus regarding the concept of ID in Latin America is not apparent, but a lack of agreement on the broad definition of disability is documented. ${ }^{9}$ 
The aforementioned debate about the meaning of ID occurring in developed countries is further complicated by culture, history, and education which may vary to a greater extent in developing countries. ${ }^{1}$ Developing nations typically view disability from an impairment or deficit model, which results in an underreporting of disability, ${ }^{16}$ although Belize, Brazil, and Chile have employed a more current activity limitations focus to identifying disability in their most recent censuses.

The $\mathrm{WHO}^{12}$ classifies ID as a mental health disorder, along with other conditions such as mental illness (e.g. schizophrenia and depression), epilepsy, and chemical dependence. The $\mathrm{PAHO}^{5}$ also grouped these conditions in a recent document promoting societal inclusion of people with mental health disorders and defined the condition as "incomplete or halted development characterized by the impairment of skills (e.g. cognitive, language, motor and social abilities). It therefore contributes to one's overall level of intelligence". Grouping these conditions may be logical from a medical standpoint, but this practice does not comply with current perceptions of ID.

The International Classification of Functioning (ICF) is designed as an adjunct to the ICD-10 and reforms the concept of disability from a deficit/impairment diagnostic model, to one that incorporates interactions between the individual and environment. ${ }^{17}$ Some Latin American countries are moving toward adopting the ICF $;{ }^{9}$ however, until there is uniform acceptance of the philosophical underpinnings and improved usability of this assessment instrument, the impairment concept of ID will persist.

There is little information on the status of people with ID in Latin America in terms of overall treatment, including legal rights, social acceptance, employment, education, community inclusion, and health care. There is a great deal of intra- and inter-cultural diversity across countries in this region, which impacts the social status of people with disabilities. Brazil, Costa Rica, and Jamaica are the only countries in the region that have achieved Most Inclusive Nation status according to the IDRM. ${ }^{9}$ Belize, Bolivia, El Salvador, Guatemala, Guyana, Honduras, Nicaragua, and Paraguay are classified as Least Inclusive, which means they lack the basic elements of social inclusion of people with disabilities. ${ }^{9}$ The condition of people with ID in most of the region may be best inferred from an article by Couch, Goetz, and Baud $^{18}$ that addressed people with physical and sensory disabilities in Guatemala. The authors observed that people with disabilities in this country led extremely difficult lives and many were pitied, overprotected, ignored, or forgotten. ${ }^{18}$ In parts of Latin America, particularly in remote areas and among the uneducated, superstitions and false beliefs regarding disability exist. ${ }^{19}$ While families usually accept responsibility for the individual with a disability, a traditional belief is that the condition is God's judgment or punishment on the family, ${ }^{20}$ although this cannot be over-generalized because there are few fixed patterns of beliefs and perceptions toward disability vary within cultures. ${ }^{21}$

It has been reported that people with ID in Latin America are often institutionalized and hidden from society in substandard and overcrowded facilities, many of which are operated by non-governmental agencies with little oversight and regulation..$^{22}$ As a result, there have been several documented cases of suspicious fire disasters, abuse and neglect that have contributed to the deaths of people with ID in this region. ${ }^{22}$ There have also been several reports of severe abuse and neglect of adults and children with ID inappropriately placed in psychiatric institutions in Uruguay, ${ }^{23}$ Mexico, ${ }^{24} \mathrm{Peru}^{25}$ and Paraguay, ${ }^{26}$ and it is likely that similar mistreatment of people with ID is pervasive throughout Latin America. ${ }^{27}$ Economic instabilities often cause governments to reduce services to this population and cultural values may interfere with pursuing services..$^{20}$ Another view is that the basic needs of people with disabilities may not be regarded as a government priority because these individuals are socially marginalized. For example, Chile has established one of the fastest-growing economies in the region, yet the extent of government support for people with ID is unclear because there is no central agency responsible for these citizens. ${ }^{22}$ This lack of action suggests that the needs of this population are not a high priority for the government in this country.

The IDRM ${ }^{9}$ provides an overview of legislation and disability rights for each Latin American country and all have enacted either adequate or some basic legal protections, with Belize identified as the lone nation that provides poor or no protections. Many countries adopted the 1990 Declaration of Caracas and subsequent Principles for the Protection of Persons with Mental Illness as legal guidelines to protect the rights of people with ID. ${ }^{22}$ However, despite ratified legislation, enforcement of legal protections is spurious. Over half the countries in this region specify that people with disabilities have rights, 14 have laws that protect this population segment, and others include disability in other legislation. Chile, Costa Rica, Dominican Republic, Ecuador, Panama, and Uruguay are the few countries that have passed laws prohibiting discrimination against persons with disabilities. In addition, Brazil, Colombia, Ecuador, Mexico, Panama, Argentina, Costa Rica, Guatemala, Nicaragua, and Uruguay have agencies responsible for the creation and coordination of disability policy, but half have not taken effective action. ${ }^{9}$ 
Poverty is a common problem among Latin Americans in general, and occurs to a greater extent among people with disabilities. Unemployment and underemployment rates are high across most of Latin America, particularly for people with disabilities, with almost $70 \%$ of this population unemployed and many who are employed actually receive no pay or low pay. ${ }^{9}$ Data from developed countries further indicate that competitive employment rates and wage earnings of people with ID are $\operatorname{low}^{28,29}$ and it is likely that this is also true for developing countries, which have few vocational rehabilitation services. Several countries have created laws/ policies designed to integrate people with disabilities in the workplace, ${ }^{9}$ but based on the language in the documents it is speculated that these mandates primarily target those with physical or sensory disabilities. Most people with disabilities in Latin America live with extended family $y^{9,18,30}$ and it has been reported that families of youth with ID, particularly those that include someone with severe ID, are more disadvantaged than families of children with other types of disabilities. ${ }^{31}$ This implies that the extreme poverty observed among people with disabilities is worse in those with ID.

The low education levels among the general population of Latin Americans contribute to high poverty rates. The majority of people in this region do not complete secondary education, although illiteracy rates have declined..$^{10}$ The limited data on youth with disabilities indicate that some countries have made legal provisions for educating this population segment, ${ }^{32}$ but again, the enforcement of these laws is dubious. Mexico made constitutional revisions that required states to provide special education to children with disabilities, including those with ID; ${ }^{20}$ however, according to a 1992 assessment, only $3 \%$ of youth with ID were receiving services $^{32}$ and these services were restricted to those attending boarding schools. In fact, of the 11 Latin American countries addressed in the United Nations Educational, Scientific, and Cultural Organization ${ }^{33}$ report, Brazil was the only country that did not provide special education services to youth with ID in segregated boarding schools. Those with severe disabilities are often denied school admission and students with various conditions are restricted to elementary education. This lack of school participation is partially attributed to the fact that parents are not informed that special education services are available. ${ }^{33}$ It is important to highlight that some Latin American countries demonstrate a progressive attitude with regard to educating children with disabilities. For example, Costa Rica approaches special education from the more current integration, rather than antiquated segregated (i.e. diagnostic) approach. ${ }^{34}$ This reflects support of inclusive education that may eventually result in greater social inclusion.

Basic human rights and services for Latin Americans with ID appear to be evolving, but progress is slow and difficult to document. The majority of countries provide some level of protection and services, but few address the global needs of this population segment. As such, it can be concluded that people with ID in this region live in poverty, and are primarily marginalized and excluded from society. Further, with the exception of providing education and eliminating abuse in some countries, there appear to be no clear plans for improving the status of this population segment in a majority of the region.

\section{Intellectual disability and health in Latin America}

Increased standards of care for people with ID have resulted in an increased life expectancy for this population, ${ }^{35,36}$ yet large disparities, compared to the general population, exist across all health domains. ${ }^{37-40}$ These disparities are particularly apparent in areas such as cardiovascular disease, ${ }^{41}$ obesity, ${ }^{42}$ vision and oral problems, ${ }^{43}$ psychological disorders, ${ }^{44}$ and co-occurring medical conditions such as epilepsy. ${ }^{45,46}$ Van Schrojenstein Lantman de Valk, Metsemakers, Haveman, and Crebolder ${ }^{47}$ found that adults with ID in the Netherlands had twice the number of health problems as those without ID. Conversely, others indicate that the health status of people with ID is generally positive and comparable to the general population. ${ }^{48,49}$ Data discrepancies can be attributed to differences in definitions of health problems and ID, inappropriate comparison samples, poor data collection methods, and variability in target population characteristics (e.g. sex, age, etiology). ${ }^{46}$ Regardless, there is general agreement that people with ID have less access to quality preventive health care that meets their unique needs, placing them at risk for chronic disease and secondary conditions. ${ }^{2}$

The knowledge base on health and ID is derived from developed countries and cannot be easily generalized to developing countries. ${ }^{4,50}$ Information on Latin Americans with ID is almost nonexistent, thus any statements about the health status or needs of this population segment are speculative. One of the few articles identified revealed that people with ID in Chile and Mexico were seldom afforded access to mental health services. ${ }^{51}$ In Chile, there is poor coordination between mental health programs and in Mexico it was speculated that most people with ID did not access services. This may be due to a high level of stigma attached to mental illness 
in Latin America. ${ }^{52}$ Sacristan Rodriguez ${ }^{51}$ also noted that funding in Mexico for research and services for ID had decreased due to economic crises. Despite the lack of data, it is reasonable to assume that the health disparities observed among people with ID in developed countries are even greater for Latin Americans with ID.

The focus of many countries in the region is preventing ID by increasing iodization, improving prenatal nutrition, and reducing exposure to teratogens, rather than improving the health and well-being of individuals living with the diagnosis. ${ }^{2,10}$ Most developing countries focus resources on developmental needs of nondisabled children, and they lack human and monetary resources to provide early detection and subsequent services to those with disabilities. ${ }^{19}$ These nations also continue to struggle with mortality and morbidity risks that are less evident in more developed nations. ${ }^{8}$ Latin American countries are often unable to meet the basic health needs of their citizens, yet lifestyle related diseases associated with affluence, such as heart disease and obesity, are an emerging problem. ${ }^{35,53}$ In addition, Latin America appears to be experiencing changes in disability demographics similar to North America and Europe; that is, as child mortality rates decline, due to improvements in medical care disability rates increase. ${ }^{19}$

Since health services for people without disabilities across the majority of Latin American countries are already considered insufficient, it is unlikely that the complex health care needs of an apparently increasing population of people with disabilities will be met. ${ }^{9}$ Only Brazil, Argentina, Chile, and Nicaragua are reported as providing adequate basic health services to people with disabilities, although the criteria for achieving this standard were not stated. ${ }^{9}$ Health insurance is typically tied to employment and, since these individuals are largely unemployed, most have no benefits. Health care is primarily provided by the government or nongovernmental agencies, but these services are hampered by a lack of resources. In addition, there is a shortage of medical professionals trained to address the needs of these individuals, particularly in rural areas. ${ }^{9}$

In a review of the basic country health profiles available on the PAHO website, over half included disability as a category under specific health problems (i.e. either a priority population group or data analyzed according to population groups), but there was no specific information regarding health needs or provision of health care services for people with ID. The health status of Latin Americans with ID is limited to reports on Peru, ${ }^{25}$ Mexico $^{24}$ and Uruguay, ${ }^{23}$ which indicate a poor standard of health care. Since the majority of Latin American countries do not provide adequate basic health protections, it can be surmised that the overall health status of people with ID in this region is similar to Peru, Mexico and Uruguay and considered undesirable.

\section{Health promotion and people with intellectual disabilities}

Preventive health for people with ID has received increased attention, associated with the paradigm shift that health is not the absence of disease or disability, 54,55 thus the presence of a diagnosis such as ID does not automatically predispose an individual to poor health. ${ }^{56}$ In 2000, the WHO and International Association for the Scientific Study of Intellectual Disabilities (IASSID) jointly released a series of reports on healthy aging and longevity in people with ID. ${ }^{57}$ The reports highlighted that special attention is required to meet the needs of those aging with ID, particularly in developing countries. It was concluded that there is a significant need for national health and social policies that provide inclusive lifespan services and supports to people with ID in the areas of health care, housing, employment, and education. ${ }^{57}$ As a result, several countries/regions (United States, Europe, Scotland, England) and agencies (Special Olympics International) have made a concerted effort to promote the health needs of this population. . $^{437,58,59}$

Despite these increased efforts, both primary and preventive health care for people with ID continues to be a global problem. Across developed and developing countries, national health care is typically inadequate and the special needs of people with ID are not addressed the same as the general population's. ${ }^{2}$ People with ID may see physicians with equal frequency as people without ID, but conditions are often undiagnosed, under diagnosed, diagnosed late, or mismanaged. ${ }^{45}$ This population receives less preventive care such as immunizations, blood pressure monitoring and cancer screening. ${ }^{60,61}$ In addition, people with ID either do not access or are not afforded opportunities to participate in health promotion or education programs. ${ }^{62}$ The health care of people with ID is perhaps best described as a "cascade of disparities" due to the compounding effects of a high prevalence of undesirable health conditions, poor attention to care needs, and lack of access to equitable health care. ${ }^{39}$

Awareness of health promotion for people with ID in Latin America is minimal and there is no clear action plan for addressing the unique needs of these individuals in this region. As previously mentioned, developing countries are focused on basic health care and preventing disabilities, therefore the needs of population subgroups are not priorities. ${ }^{50}$ The PAHO Executive Committee ${ }^{62}$ recently adopted a resolution affirming the 
rights of people with disabilities to enjoy the "highest attainable standard of health". People with disabilities are identified in the health priorities of some countries, and many countries, such as Mexico, have developed initiatives for the inclusion of people with disabilities in national health programs, but these proposals are typically unfunded or under funded. ${ }^{9}$ The $\mathrm{PAHO}^{5}$ suggested that positive attitudes, appropriate programs, and empowerment would expedite development of health policies, programs and services for people with ID. Apart from this extremely general recommendation, no Latin American countries have created specific health initiatives for people with ID. Thus, it can be assumed that the cascade of health disparities experienced by people with ID in developed countries ${ }^{39}$ is even more pronounced for those with ID in Latin America.

Health care, promotion, and education services designed for the general population should also be delivered to people with ID, but modified to accommodate cognitive processing differences and literacy. ${ }^{4}$ As such, people with ID should also be subsumed in a nation's overall health mandates / targets. The $\mathrm{PAHO}^{10}$ target promotion areas for the Americas include: community health, family and population health, adolescent and youth health, disability, ageing, maternal health, indigenous people, food and nutrition, mental health, drug use and dependency, sexual and reproductive health, and oral health. It is commendable that disability is included as a main heading in the document, but the information appears biased toward people with physical disabilities, based on statements about access and mobility as major barriers and an emphasis on rehabilitation. People with ID are mentioned under the main heading of family and population health, as part of a subcategory on emerging problems that includes a small section on disability. Interestingly, this group was not addressed in the section on mental health, which is contradictory to other PAHO documents. ${ }^{5}$ Theoretically, people with ID appear to be included in this regional health initiative, but it is doubtful that this has translated into actual service provision.

The IASSID ${ }^{64}$ identified 15 specific health targets for people with ID that should be assessed, reviewed and/or treated regularly: oral health, vision, nutrition (i.e. underweight and obesity), chronic constipation, epilepsy, thyroid disease, mental health, gastro-esophageal reflux disease and Helicobacter pylori, osteoporosis, medications, immunizations, physical activity/exercise, comprehensive health, etiology/genetics, and women's health. Many of these overlap with general population health needs, but several are unique, such as chronic constipation. There are numerous published studies or programs designed to address several of these areas, such as women's health, ${ }^{65}$ general health screening, ${ }^{66}$ mental health, ${ }^{67}$ bone health ${ }^{68}$ exercise and nutrition, ${ }^{69,70}$ healthy lifestyles, ${ }^{71}$ and oral health. ${ }^{72}$ Other programs have addressed related topics such as health advocacy and communication, ${ }^{73,74}$ cancer screening, ${ }^{75}$ tobacco use prevention, ${ }^{76}$ unintentional injury, ${ }^{77}$ and sexual health and behavior. ${ }^{78}$ These studies represent a relatively recent shift from descriptive to intervention research in health and ID, which is necessary to advance the health status of this population. ${ }^{54}$

The aforementioned interventions / promotion programs were designed to address health in people with ID in developed countries, reflecting neither the needs nor cultural norms of developing countries. ${ }^{2}$ Socioeconomic disadvantages, lack of knowledge among care providers and professionals, negative societal attitudes, communication difficulties, poor service coordination, lack of qualified personnel, and behavioral problems are identified as barriers to health care in people with ID from developed countries. ${ }^{37,62}$ These same barriers can be generalized to Latin Americans with ID, but are likely compounded by an overall lack of health and disability services.

Krahn and associate ${ }^{39}$ outlined four major actions to alleviate observed health disparities in this population: ${ }^{1}$ promote early screening, inclusion, and self-determination in quality health care, ${ }^{2}$ reduce co-occurring and secondary conditions; ${ }^{3}$ empower caregivers and family to help meet health care needs; and ${ }^{4}$ promote healthy behaviors. Others have identified additional key concepts, such as adopting a lifespan approach to meeting the needs of people with ID, increasing the quality and quantity of health care workers, recognizing the contributions of adults with ID to society, and improving collaboration and communication between agencies. ${ }^{2,62}$ There are several model programs that have incorporated these actions to meet various health needs of people with $\mathrm{ID}_{;}{ }^{39}$ however the applicability of these recommendations to regions that may lack the necessary infrastructure or resources is questionable.

Broad implementation of these recommendations in developed countries has been a slow process. In the United States, deinstitutionalization and societal integration of people with ID has occurred over the past 40 years, yet government reports addressing the unique health needs of this population have been published only in the past five years. ${ }^{58}$ Even with laws enforcing equal protection and nondiscrimination, people with ID continue to be marginalized in all aspects of society in the United States for many of the same issues facing developing countries: lack of resources and financial appropriations, poor coordination/communication between agencies, lack of empowerment and knowledge 
among individuals with ID and their care providers, lack of trained professionals to address needs, and negative societal attitudes. The difficulties promoting health for people with ID encountered by developed countries will be compounded in Latin American countries that have not passed or do not enforce federal protections ensuring basic civil rights and social integration. In addition, most countries in the world are struggling to create and implement action plans to address the United Nations Millennium Goals ${ }^{79}$ of eradicating hunger/malnutrition, decreasing child mortality, improving maternal health, combating HIV/ AIDS and other infectious diseases, improving access to safe drinking water, and improving access to essential medications. Therefore, addressing the additional health care needs of people with ID may over tax the already limited resources of developing countries in Latin America.

Despite the difficulties facing Latin America in providing health services to people with ID, certain countries in this region appear to be in the process of major disability and health reforms. Over the past seven years Mexico has undergone a nation-wide health system transformation to address problems ranging from the influence of poverty on health to the emergence of lifestyle related diseases (e.g. obesity). The Popular Health (Seguro Popular) plan was initiated to provide health care to 50 million, mostly poor, citizens that previously were excluded from social insurance. ${ }^{80}$ Results from the reform plan are encouraging and this may also be a promising avenue for Mexicans with ID to receive appropriate health care, but it is not clear if the needs of these individuals are being addressed. In addition, reforms in Mexican disability services were initiated after disclosure of severe abuse and neglect in state mental institutions. Publication of the report prompted the first ever visit by a Mexican health secretary to one of these facilities, resulting in an immediate investment in facility improvement and staff training. ${ }^{81}$ Many needed reforms for people with ID, such as community-based services, are already established in federal law, but not enforced. ${ }^{24}$ Although the impact of Mexican health and disability reforms on health care and promotion has yet to be determined, this movement toward better global care and treatment of people with ID could provide the needed framework to promote health for this population segment in this country.

Health promotion programs and interventions must address multiple micro- and macro-levels that include the individual, families/care givers, government and non-government agencies. ${ }^{39}$ There are many variables within these areas that should be considered according to relevance and influence within a particular country. For the purposes of this discussion, four specific levels be addressed: national and international agencies, schools, parents/families and the individual. Related factors such as professional training will not be discussed and the reader is referred to other resources for this information. ${ }^{39}$

There are several well accepted and universal models for health promotion programs, but the Ottawa Charter for Health Promotion continues to guide global practice. ${ }^{82}$ Four action areas are identified as the basis for health promotion strategies: create community-based health promotion policies, create supportive health environments, teach personal skills, and reorient health services. ${ }^{82}$ Latin American countries can develop programs for people with ID by adapting this process according to specific culture, geography, national health initiatives, legal mandates, and existing infrastructure/ resources. Similar, albeit small-scale, efforts have occurred in other developing countries. The South-East Asia Region (SEARO) of WHO created a manual to train community-based rehabilitation workers how to work with people with ID in rural and remote areas of Thailand and India. ${ }^{83}$ Consultants are provided to train people using the manual as a resource, and SEARO is working with a non-governmental agency to develop curricula and training centers in other member countries.

Latin American countries could follow suite by developing cooperative agreements between international (WHO), regional (PAHO), national (countryspecific) and non-governmental agencies to address health promotion and health policies for people with ID. For example, in Mexico the PAHO could work with the National Council on Mental Health (government) and advocacy groups (non-government) such as VOZ Pro Salud Mental and Fundación Mexicana para la Rehabilitación del Enfermo Mental to develop approaches to health issues in this population segment. Special Olympics International would also be a particularly effective non-governmental avenue to implement health promotion interventions through its Healthy Athletes Program. Launched in Latin America in 2001, the program has provided various health screenings for over 13000 athletes in that region. The structure of this well-established and organized program could serve as a template to develop broader health promotion programs for people with ID in Mexico.

Family involvement will be a critical component to health promotion programs in Latin America. It is well established that family is a central component of Latin American culture and many people with ID are cared for by family members throughout their lives. ${ }^{84}$ Research on Hispanic families of people with ID is largely based on immigrants, but indicates that the presence of ID has a limited impact on the values Mexican American 
and Puerto Rican American parents hold for their children. ${ }^{85}$ Therefore, Hispanic families likely value health for family members with ID and this is an important starting point for accessing services; however, low education levels may interfere with the family's ability to operationalize their health values. As previously noted, poverty is higher among families of youth with ID in developing countries. ${ }^{31}$ Lack of education typically accompanies poverty and it is reasonable to conclude that many parents of youth with ID in Latin America are largely un- or under- educated. Low education levels will affect the ability of parents to access and maximize health services for their children. Blanche ${ }^{86}$ found that an impoverished El Salvadoran immigrant to the United States lacked the necessary finances for things such as transportation and knowledge (e.g. ability to ask pertinent questions) to access services for her child with developmental delays. This is not surprising because illiteracy rates for Latin Americans are high, and since mothers are primary caregivers in most cultures, the ability of people with ID in this region to access health services will be dictated, to a large extent, by the mother's education level. ${ }^{87}$ In addition, Sales-Provance, Erickson, and Reid ${ }^{88}$ found that American Hispanics without high school educations were more prone to folk beliefs related to causes and cures for disabilities, which may hinder accessing quality health services.

The issue of parent/ family education is compounded by geography and ethnicity. For example, indigenous Latin Americans often do not speak Spanish and may not have access to health promotion materials in their native language. There is a large disparity in illiteracy rates between whites (8\%) and blacks (22\%) in Brazil, suggesting the latter population would have greater difficulty accessing health programs ${ }^{89}$ It follows that the magnitude of disparity may increase when an ID is calculated into the equation. That is, a Brazilian black child with ID may have less access to health resources than a Brazilian white child with ID. Geographical isolation will also impact health promotion efforts because it is difficult to provide services to disperse and geographically isolated small population segments, such as people with ID. ${ }^{90}$ For example, although rural areas in Guatemala are the most heavily populated, the majority of health and special education services are located in the capital city. ${ }^{19}$ There are no demographic data on Latin Americans with ID according to ethnicity, geography, or socioeconomic status, but this must be considered in health promotion programs for these individuals.

Another important resource for promoting health among people with ID in Latin America is schools. Although many Latin American countries have not achieved social integration of people with ID, educa- tional services for these individuals are provided to a certain degree in some countries. The $\mathrm{PAHO}^{10}$ states that Latin America has implemented Health-Promoting Schools Initiatives to provide comprehensive health education, healthy and supportive environments, and health services, nutrition and physical activity programs. Latin American children with ID who attend school, typically do so in segregated settings, where it is unknown if these initiatives are implemented. However, since these initiatives are already developed, it would be an efficient use of resources to adapt the existing curricula for youth with ID and avoid redundancy in policies.

A final, and perhaps the most important, aspect of health promotion for people with ID is self-determination and person-centered services. The ability of people with ID to be their own change agents in health care will largely depend on government and social attitudes, as well as enforcement of civil rights. In developed countries, there has been a movement to empower and teach people with ID decision and choice making skills related to health care. ${ }^{91}$ This occurs by increasing basic health knowledge using culturally relevant materials, utilizing appropriate instructional methods, teaching communication skills, and building support networks among the community, family and friends. ${ }^{82}$ Allan and Dip ${ }^{92}$ found that people with ID value their health and, when provided sufficient time, people with ID can discuss their health concerns with professionals. Allowing people with ID more autonomy and participation in their own health care can lead to an increased use of health services, more satisfaction with health services and fewer unmet health needs. ${ }^{93}$

\section{Summary}

Latin America is undergoing many evolutions in general health and disability reform, and this is an opportune time to address the specific health needs of people with ID. To accomplish this, countries in the region need to adapt research-based best practices in health promotion according to individual culture, geography, philosophy, politics, and resources; as well as existing national health initiatives. However, the most important and fundamental aspects of developing health promotion programs for this population segment is for Latin American governments to recognize the inherent rights of people with ID to achieve good health and enforce legal mandates accordingly. In addition, that these individuals are contributing members of society and stakeholders in community health care. Once this is accomplished, Latin American countries will be able to advance health promotion for individuals with ID. 


\section{References}

I. Fujiura G, Park HJ, Rutkowsk-Kmitta V. Disability statistics in the developing world:A reflection on the meaning of our numbers. J Appl Res Intellect Disabil 2005; 18:295-304.

2. World Health Organization. Ageing and intellectual disabilities - improving longevity and promoting healthy ageing: Summative report. Geneva, Switzerland:WHO, 2000.

3. Durkin M.The epidemiology of developmental disabilities in low-income countries. Ment Retard Dev Disabil Res Rev 2002;8:206-2II.

4. Evenhuis $\mathrm{H}$, Henderson CM, Beange $H$, Lennox N, Chicoine B. Healthy ageing-adults with intellectual disabilities: Physical health issues. Geneva, Switzerland:WHO, 2000.

5. Pan American Health Organization. Mental Health: Stop exclusion-dare to care. Washington, DC; Pan American Health Organization, 2001. 6. Batshaw ML. Children with disabilities. 5th ed. Baltimore, MD: Paul H. Brookes, 2002.

7.Veney J. Introduction to the countries. In: Fried BJ, Gaydos LM, editors. World health systems: Challenges and perspectives. Chicago, IL: Health Administration Press, 2002:67-82.

8. Lloyd-Sherlock P.Argentina. In: Fried BJ, Gaydos LM, editors. World health systems: Challenges and perspectives. Chicago, IL: Health Administration Press, 2002:83-97.

9. International Disability Rights Monitor. Regional report of the Americas [Online]. 2004 [cited 2007 Jan 30]; Available from: URL: http://www. ideanet.org/content.cfm?id=585D77\&memberMenuid $=0$.

10. Pan American Health Organization. Health in the Americas (Vol I). Washington, DC:WHO, 2002.

II. Greenspan S. What is meant by mental retardation? Int Rev Psychiatry, 1999;11:6-18.

12. World Health Organization. ICD- 10 guide for mental retardation.

Geneva, Switzerland:WHO, 1996.

13.American Association on Mental Retardation. Definition, Classification, and Systems of Supports. 10th ed.Washington, DC:American Association on Mental Retardation, 2002.

14.American Psychiatric Association. Diagnostic and statistical manual of mental disorders. 4th ed. Washington, DC: American Psychiatric Association, 1994.

15. Walker Jr WO, Johnson CP. Mental retardation: Overview and diagnosis. Ped Rev 2006;27:204-2I2.

16. Chamie M. Survey design strategies for the study of disability. World Health Stat Q 1989;42:122-140.

17.World Health Organization. ICF Introduction [Online]. 200 I [cited 2006 Feb I];Available from: URL: http://www3.who.int/icf/intros//CF-EngIntro.pdf.

18. Couch RH, Goetz JP, Baud H. Living with disability in Guatemala. J Rehabil 199|;57:46-5I.

19. Replogle J. Guatemala's children face a lifetime of challenges. Lancet 2005;365: 1757- 1758 .

20. Cieloha CD. Special education in the context of national development: The case of Mexico. Paper presented at the 67th annual meeting of the American Educational Research Association, San Francisco, CA; 1986. ERIC Document Reproduction Service No. ED 27I 916. Cited by: Shepherd TL, Contreras D, Brown D. Special education in Mexico: One community's response. Teach Except Child 2002;34:8-II.

21. McCallion P, Janicki M, Grant-Griffin. Exploring the impact of culture and acculturation on older families caregiving for persons with developmental disabilities. Fam Relat 1997;46:347-357.

22. Sims C. Latin America's disabled: Unsafely hidden away [Online]. New York Times 1997 Oct I [cited 2007 Feb I];Available from:URL: http:// query.nytimes.com/gst/fullpage.html.
23. Mental Disability Rights International. Human rights \& mental health in Uruguay. Washington, DC: Mental Disability Rights International, 1995.

24. Mental Disability Rights International. Human rights \& mental health in Mexico. Washington, D.C: Mental Disability Rights International, 2002.

25. Mental Disability Rights International. Human rights \& mental health in Peru. Washington, DC: Mental Disability Rights International, 2004.

26. Hammes L. Paraguay: Human rights for the mentally disabled. NACL Report on the Americas [serial online] 2004 Mar-April [cited 2007 Jan 30]; 37(5); Available from:URL:http://www.nacla.org/art_display. php?art $=2367$.

27. Hillman AA. Human rights and deinstitutionalization:A success story in the Americas. Rev Panam Salud Publica 2005; I8:374-379.

28.Van Schrojenstein Lantman-de Valk HMJ, te Wierik MJM, van den Akker M,Wullink M, Schellevis RG, Dinant GJ, Metsemakers JFM. Brief research report: morbidity and health care use in people with intellectual disabilities in general practice: First results of a survey in the Netherlands. J Pol Pract Intellect Disabil 2004; 1: 107-109.

29. Olney MF, Kennedy J. National estimates of vocational service utilization and job placement rates for adults with mental retardation. Ment Retard 200 I;39:32-39.

30. De Vos S. Extended family living among older people in six Latin American countries.J Gerontol 1990;45:S87-S94.

3I. Stein Z, Belmont L, Durkin M. Mild mental retardation and severe mental retardation compared: Experiences in eight less developed countries 1987;(suppl 44):89-96.

32. García G. Una demanda que toca la perta. Mira 1993;167:17-21. Cited by: Fletcher TV, Kaufman de Lopez CK.A Mexican perspective on learning disabilities.J Learn Disabil 1995;28:530-534, 544.

33. United Nations Educational, Scientific, and Cultural Organization. Review of the present situation in special needs education. Paris: United Nations Educational, Scientific, and Cultural Organization; 1995. Report UNESCO-ED-95/WS-7.

34. Stough LM. Special education and severe disabilities in Costa Rica: Developing inclusion in a developing country. Res Prac Persons Severe Disabil 2003;28:7-15.

35. Patja K, Livanainen M,Vesala H, Oksanen H, Ruoppila I. Life expectancy of people with intellectual disability: A 35-year follow-up study.J Intellect Disabil Res 2000;44:591-599.

36. World Health Organization. The world health report 2002. Reducing risks, promoting healthy life. Geneva, Switzerland:WHO, 2002.

37. Fisher K. Health disparities and mental retardation.J Nurs Scholarsh 2004;36:48-53.

38. Horwitz SM, Kerker BD, Owens PL, Zigler E. The health status and needs of individuals with mental retardation [Online]. 2000 [cited 2005 Mar I];Available from: URL: http://www.specialolympics.org/Special+O lympics+Public+Website/English/Initiatives/Research/Health_Research/ Health+Status+and+Needs.htm.

39. Krahn GL, Hammond L, Turner A.A cascade of disparities: Health and health care access for people with intellectual disabilities. Ment Retard Dev Disabil Res Rev 2006; 12:70-82.

40. Sutherland G, Couch MA, lacono T. Health issues for adults with developmental disability. Res Dev Disabil 2002;23:422-445.

41. Draheim CC. Cardiovascular disease prevalence and risk factors of persons with mental retardation. Ment Retard Dev Disabil Res Rev 2006; 12:3-12.

42. Rimmer JH,Yamaki K. Obesity and intellectual disability. Ment Retard Dev Disabil Res Rev 2006; 12:22-27.

43. Owens PL, Kerker BD, Zigler E, Horwitz SM.Vision and oral health needs of individuals with intellectual disability. Ment Retard Dev Disabil Res Rev 2006; 12:38-40.

44. Hatton C. Psychosocial interventions for adults with intellectual disabilities and mental health problems: A review. J Ment Health 2002; | 1:357-373. 
45. Beange H, McElduff A, Baker W. Medical disorders of adults with mental retardation:A population study. Am J Ment Retard 1995;99:595-604. 46. Jansen DEMC, Krol B, Groothoff,JW, Post D. People with intellectual disability and their health problems:A review of comparative studies. J Intellect Disabil Res 2004;48:93-102.

47.Van Schrojenstein Lantman-de Valk HMJ, Metsemakers JFM, Haveman MJ, Crebolder HFJM. Health problems in people with intellectual disability in general practice: A comparitive study. Fam Pract 2000; 17:405-407. 48. Kapell D, Nightingale B, Rodriguez A, Lee JH, Zigman WB, Schupf $\mathrm{N}$. Prevalence of chronic medical conditions in adults with mental retardation: comparison with the general population. Ment Retard 1998;36(4):269-279.

49. Freedman RI, Chassler D. Physical and behavioral health of adults with mental retardation across residential settings. Public Health Rep 2004; II9:40I-408.

50.Van Schrojenstein Lantman-de Valk HMJ. Health in people with intellectual disabilities: Current knowledge and gaps in knowledge. J Appl Res Intellect Disabil 2005; I8:325-333.

51. Sacristan Rodriguez J. Mental health in Spanish-speaking mentally retarded people:The state of the art.Aust N Z J Dev Disabil 1988;14:27-30. 52. Acuña C, Bolis M. Stigmatization and access to health care in Latin America: Challenges and perspectives [Online]. 2005 [cited 2007 Feb I];Available from: URL:http://www.paho.org/English/DPM/SHD/HP/legstigmatization-eng.pdf.

53. Barcelo A. Cardiovascular diseases in Latin America and the Caribbean. Lancet 2000;368:625-626.

54. Frey GC, Temple VA, Stanish H. Introduction: Preventive health and individuals with mental retardation. Ment Retard Dev Disabil Res Rev 2006; I2:I-2.

55. Rimmer JH. Health promotion for people with disabilities: the emerging paradigm shift from disability prevention to prevention of secondary conditions. Phys Ther 1999;79:495-501.

56. Tighe CA. 'Working at disability':A qualitative study of the meaning of health and disability for women with physical impairments. Disabil Soc 200I;16:5II-529.

57. Janicki M. Toward a rational strategy for promoting healthy aging amongst people with intellectual disabilities. J Appl Res Intellect Disabil 2001; I4:171-174.

58. United States Public Health Service. Closing the gap:A national blueprint for improving the health of individuals with mental retardation. Washington, DC: United States Department of Health and Human Services, 2002.

59. Commission for Healthcare Audit and Inspection. Draft three-year strategic plan for assessing and encouraging improvement in the health and healthcare of adults with learning disabilities 2006-2009. London, UK Commission for Healthcare Audit and Inspection, 2005.

60. Kerr MP, Richards D, Glover G. Primary care for people with intellectual disability-a group practice survey. J Appl Res Intellect Disabil 1996;9:347-352.

61. Stein K,Allen N. Cross sectional survey of cervical cancer screening in women with learning disability. BMJ 1999;3:18-64.

62. Durvasula $S$, Beanage $H$. Health inequalities in people with intellectual disability: Strategies for improvement. Health Promot J Australia [serial online] 200I [cited 2007 Feb I], I I. Available from:URL:http://www. healthpromotion.org.au/journal/previous/200I_I/index.html. 63. Pan American Health Organization. Disability: Prevention and rehabilitation in the context of the right to the enjoyment of the highest attainable standard of health and other related rights [Online]. 2006 Sept 25-29 [cited 2007 jan 7]; Available from:URL: http://www.paho. org/english/gov/cd/CD47-15-e.pdf.

64. International Association for the Scientific Study of Intellectual Disabilities. Health guidelines for adults with an intellectual disability
[Online]. 2002 [cited 2006 Mar I];Available from: URL: http://www.iassid. org/pdf/healthguidelines-2002.pdf.

65. Lunsky Y, Straiko A,Armstrong S. Women be health: Evaluation of a women's health curriculum for women with intellectual disabilities. J Appl Res Intellect Disabil 2003;16:247-253.

66. Cooper S-A, Morrison J, Melville C, Finlayson J,Allan L, Martin G et al. Improving the health of people with intellectual disabilities: Outcomes of a health screening programme after I year.J Intellect Disabil Res 2006;50:667-677.

67. Gratsa A, Spiller MJ, Holt G, Joyce T, Hardy S, Bouras N. Developing a mental health guide for families and carers of people with intellectual disabilities.J Appl Res Intellect Disabil 2007;20:77-86.

68. Tohill C, Laverty A. Sunshine, diet and mobility for health bones-an intervention study designed to implement these standards into the daily routine in an at risk population of adults with intellectual disability. J Intellect Dev Disabil 200I;26:2I7-23I.

69. Mann J, Zhou H, McDermott S, Poston MB. Healthy behavior change of adults with mental retardation:Attendance in a health promotion program. Am J Ment Retard 2006; I I :62-73.

70. Marks B, Heller T, Sisirak J. Exercise and nutrition health education curriculum for adults with developmental disabilities. 3 rd ed. Chicago: Rehabilitation Research and Training Center on Aging with Developmental Disabilities, University of Illinois at Chicago, 2006.

7I. Drum CE, Krahn G, Horner-Johnson W. Healthy lifestyles curriculum for people with intellectual and other disabilities. J Intellect Disabil Res 2004;48:454.

72. Shyama M,AI-Mutawa SA, Honkala S, Honkala E. Supervised toothbrushing and oral health education program in Kuwait for children and young adults with Down syndrome. Spec Care Dentist 2003;23:94-99. 73. Harper DC, Wadsworth JS. Improving health care communication for persons with mental retardation. Public Health Rep 1992; 107:297-302. 74. Lennox N, Taylor M, Rey-Conde T, Bain C, Boyle FM, Purdie DM. Ask for it: Development of a health advocacy intervention for adults with intellectual disability and their general practitioners. Health Promot Int 2004;19:167-175.

75. Davies N, Duff M. Breast cancer screening for older women with intellectual disability living in community group homes.J Intellect Disabil Res 2001;45:253-257.

76. Tracy J, Hosken R. The importance of smoking education and preventative health strategies for people with intellectual disability. J Intellect Disabil Res 1997;41:416-22I.

77. Sherrard J, Ozanne-Smith J, Staines C. Prevention of unintentional injury to people with intellectual disability:A review of the evidence. J Intellect Disabil Res 2004;48:639-645.

78. Whitehouse MA, McCabe MP. Sex education programs for people with intellectual disabilities: How effective are they? Educ Train Ment Retard Dev Disabil 1997;32:229-240.

79. United Nations. Millennium development goals report [Online]. 2006 [cited 2007 Jan 30];Available from: URL: http://mdgs.un.org/unsd/mdg/ Resources/Static/Products/Progress2006/MDGReport2006.pdf. 80. Frenk J. Bridging the divide: Global lessons from evidence-based health policy in Mexico. Lancet, 2006;368:954-961.

81. LaFranchi H.A three-year study spotlights horrific conditions in Mexico's mental institutions. Christian Science Monitor 2000 Feb 23;92(63): 1

82. Marks B, Heller T. Bridging the equity gap: Health promotion for adults with intellectual and developmental disabilities. Nurs Clin North Am 2003;38:205-228.

83. Narayan, J. Intellectual disability:A manual for CBR workers [Online]. $2003 \mathrm{Mar}$ [cited $2007 \mathrm{Feb}$ 2]; Available from: URL: http://www.searo.who. int/LinkFiles/Technical_documents_Intellectual_Disability_a_Manual_for_ CBR_Worker.pdf. 
84.Alvarez LI.A short course in sensitivity training. Teach Except Child 1998;31:74-77.

85. Arcia E, Reyes-Blanes ME,Vazquez-Montilla E. Constructions and reconstructions: Latino parents' values for children.J Child Fam Stud 2000;9:333-350.

86. Blanche El.Alma: Coping with culture, poverty, and disability.Am J Occup Ther 1996;50:265-276.

87. Morales S. Bridge over troubled waters: Collaboration between the United States and Mexico on behalf of individuals with disabilities. Bilingual $\operatorname{Rev}$ 1999;24:109-20.

88. Sales-Provance MB, Erickson JG, Reed J. Disabilities as viewed by four generations of one Hispanic family. Am J Speech Lang Pathol 2002; |1:151-62.
89. Louzano, P. Developing educational equity indicators in Latin America [Online]. 200I May [cited 2007 Feb I];Available from: URL: http://siri. unesco.cl/medios/pdf/Documentos_tecnicos/equity_ind_alc.PDF. 90. Stough LM,Aguirre-Roy AR. Learning disabilities in Costa Rica: Challenges for an "army of teachers".J Learn Disabil 1997;30:566-7I.

91. Cea CD, Fisher CB. Health care decision-making by adults with mental retardation. Ment Retard 2003;41:78-87.

92. Allan E, Dip HV. Learning disability: Promoting health equality in the community. Nurs Stand 1999; I3:21-27.

93. Heller T, Miller AB, Hsieh K. Impact of a consumer-directed family support program on adults with developmental disabilities and their family caregivers. Fam Relat 1999;48:419-427. 